\title{
Recurrent syncope
}

\section{M Massin, C Coremans}

\section{Answers on p 202.}

A 3 year old previously healthy boy was admitted to the emergency room with a three day history of recurrent syncope. Physical examination showed a regular bradycardia. He was haemodynamically stable. Figure 1 shows his admission electrocardiogram (ECG).

\section{QUESTIONS}

(1) What does his ECG show?

(2) What diagnosis would you consider?

(3) What other investigations would you consider?

(4) How would you treat this patient? $\ldots \ldots \ldots \ldots \ldots \ldots \ldots$

Authors' affiliations

M M Massin, C Coremans, Division of Paediatric Cardiology, University of Liege, Belgium

Correspondence to: DrM M Massin, Division of Paediatric Cardiology, CHR Citadelle (University of Liege), Boulevard du $12^{\mathrm{è}}$ de Ligne, 1, B-4000 Liege, Belgium; martial.massin@chrcitadelle.be

Submitted 18 March 2004

Accepted 23 April 2004

Funding: We thank the Belgian "National Foundation for Research on Paediatric Cardiology" for financial support.
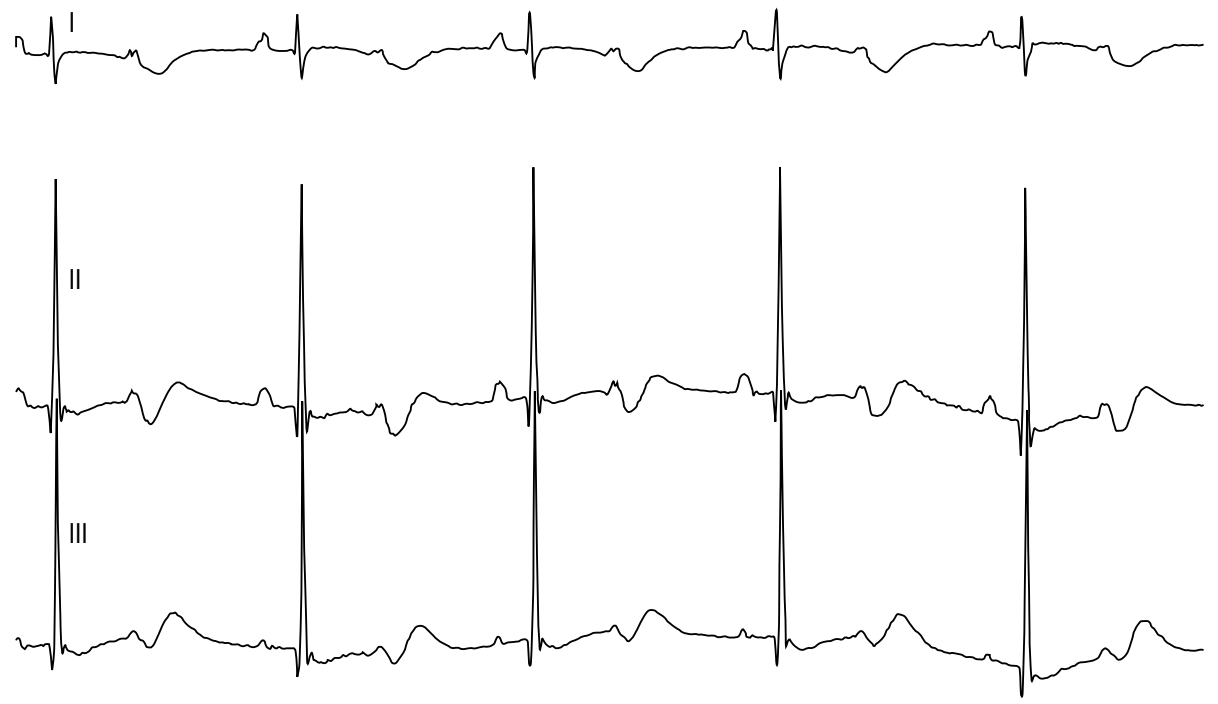

Figure 1 Leads S1, S2, and S3 of the ECG obtained at the admission.

FILLER

In praise of old technology

Y ou know how it is. The post-take ward round in a multi-bedded area. Mrs X is elderly and very deaf. Her hearing aid only produces a high pitch whine despite, or perhaps even because of, the admitting SHO's attempts to rectify the electronics (it could have been worse: many years ago, when transistor radios with miniature ear pieces were the latest technology, one house officer had mistaken the radio for a hearing aid and subjected a similar woman to the "top twenty", as it was then known, for half an hour while taking a history and concluded, incorrectly, that she was confused). Back to our original woman. A history was retaken from the patient with the physician shouting the relevant questions. Confidentiality was not assured and the next day the patient received a get well card from the patient in the next bed.

What is the point of all this? There is something to be said for old established technology. I do not refer to ear trumpets, although every geriatrician ought to have one, but rather to the stethoscope. Unless such patients have bilateral severe nerve deafness the patient should put the stethoscope earpieces in her ears and the physician should speak, not shout, into the diaphragm as if it were a microphone.

P D Welsby Western General Hospital, Edinburgh EH4 2XU, UK; p.welsby@ed.ac.uk 